\title{
ANÁLISE ERGONÔMICA DOS NÍVEIS DE ILUMINAMENTO EM SALAS DE AULAS DE UMA INSTITUIÇÃO DE ENSINO SUPERIOR DO SEMIÁRIDO
}

Versão do autor aceita publicada online: 20 dez. 2021

Publicado online: 06 jan. 2022

Como citar esse artigo - American Psychological Association (APA): Gomes, L. B. N., Lucena, A. D., \& Oliveira, F. N. (2022). Análise ergonômica dos níveis de iluminamento em salas de aulas de uma instituição de ensino superior do semiárido. Exacta. DOI: https://doi.org/10.5585/exactaep.2022.20519.

\section{Laura Beatriz Nogueira Gomes}

https://orcid.org/0000-0002-5361-8109

Universidade Federal Rural do Semi-árido

Bacharel em Ciência e Tecnologia pela Universidade Federal Rural do Semi-árido e atualmente graduanda em Engenharia de Produção pela mesma Instituição de ensino.

\section{André Duarte Lucena}

https://orcid.org/0000-0003-0181-4260

Universidade Federal Rural do Semi-árido

Professor de Engenharia de Produção do Departamento de Engenharia e Ciências Ambientais da Universidade Federal Rural do Semi-árido. Atua principalmente nas áreas de ergonomia, segurança e engenharia do trabalho.

\section{Fabrícia Nascimento de Oliveira}

https://orcid.org/0000-0002-0333-0035

Universidade Federal Rural do Semi-árido

Professora de Engenharia de Produção do Departamento de Engenharia e Ciências Ambientais da Universidade Federal Rural do Semi-árido. Atua principalmente nas áreas de segurança do trabalho, higiene ocupacional e ergonomia.

Resumo: O objetivo dessa pesquisa foi analisar os níveis de iluminamento de salas de aula de uma instituição de ensino superior. Realizou-se um estudo de caso utilizando-se luxímetro digital para coleta de dados e comparou-se os resultados com os parâmetros da Norma da Associação Brasileira de Normas Técnicas - ABNT NBR ISO/CIE 8995-1:2013. Em cada ambiente realizou-se leituras em 7 pontos nos 3 turnos e para a análise dos dados foram considerados aspectos como a área das salas, o turno de coleta e a alocação da edificação. Os resultados apontam que algumas áreas das salas de aula, dependendo do turno e da incidência da iluminação natural, não atendem os requisitos mínimos exigidos pela norma, podendo gerar prejuízos no desempenho das atividades acadêmicas. Portanto, é necessário que ocorra manutenção periódica nos sistemas de iluminação das salas de aula para que essas se adequem às recomendações da norma atendendo assim os requisitos ergonômicos.

Palavras-chave: Aspectos ergonômicos. Ambiente escolar. Conforto lumínico. 


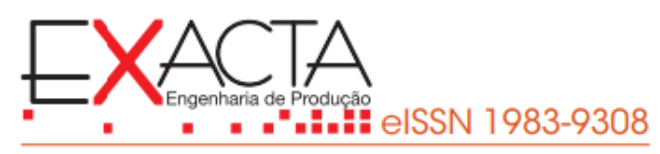

Abstract: The aim of this research was to analyze the lighting levels of classrooms at a university. A case study was carried out using a digital luximeter for data collection and the results were compared with the parameters of the standard of Associação Brasileira de Normas Técnicas - ABNT NBR ISO/CIE 8995-1:2013. In each classroom data collection was performed at 7 points in the 3 shifts, and to analyze data were considered aspects such as the area of the rooms, the collection shift and the allocation of the building. The results indicate that some areas of the classrooms, depending on the shift and the incidence of natural lighting, do not comply with the minimum values required by the standard, which can lead to losses in the performance of academic activities. Therefore, periodic maintenance is necessary in the classroom lighting systems so that they adapt to the standard's recommendations, thus meeting the ergonomic requirements.

Keywords: Ergonomic aspects. School environment. Light comfort.

\section{Introdução}

Atividades acadêmicas sejam de ensino, pesquisa ou extênsão, geralmente envolvem uma grande quantidade de pessoas e demandam tempo para o desenvolvimento dessas tarefas em ambientes de estudo. No ambiente escolar, diversos fatores influenciam diretamente na iluminação considerada ideal, como a orientação e a localização da edificação, as janelas presentes em cada sala de aula, a distribuição da iluminação artificial que deve ser uniforme, os tipos e quantidades de luminárias utilizadas, as dimensões do ambiente, o pé direito, dentre outros fatores.

A iluminação de um ambiente pode ser natural, artificial ou uma combinação de ambos. A iluminação natural promove benefícios à saúde e ao bem-estar humano ao passo que a iluminação artificial também é necessária, pois permitiu ao ser humano o uso dos espaços e a realização de atividades em que não havia luz natural (Moraes \& Claro, 2013). Nesse contexto, a combinação da iluminação artificial e natural em ambientes escolares é imprescindível para um melhor rendimento de alunos, professores e pesquisadores. A iluminação é um dos fatores físicos que influencia nas condições de trabalho de professores e demais usuários (Losekan et al., 2021). Em ambientes de estudo, tal como bibliotecas, a iluminância é um dos fatores ergonômicos ambientais que quando não adequados gera desconforto aos usuários (Mendes \& Bergiante, 2018). 


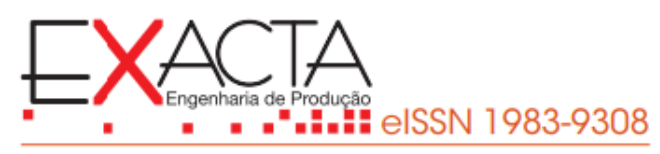

\section{Fundamentação teórica}

A educação é um aspecto fundamental para a sociedade, uma vez que está relacionado ao desenvolvimento nos âmbitos humano, tecnológico, cultural, econômico, da cidadania, entre outros. De acordo com a Constituição Federal brasileira (Brasil, 1988), a educação tem como objetivo o desenvolvimento pleno do indivíduo, a formação para cidadania e para o trabalho. Por tal relevância, os ambientes escolares, incluindo os de instituições de ensino superior, são objeto de estudo e intervenção de várias áreas do conhecimento, inclusive do conforto ambiental, considerando os aspectos térmicos, acústicos, visuais, bem como os lumínicos, dentre outros (Kowaltowski, 2021). Segundo Bortolan, Ferreira e Tezza (2020), considerando o conforto visual que compreende aspectos visuais, não visuais e psicológicos, a iluminância pode ser avaliada de acordo com o nível de conforto e o desempenho exigido pela tarefa. Porém, no presente estudo, optou-se pela avaliação de acordo com aspectos normativos do contexto de segurança e ergonomia.

Em relação aos aspectos lumínicos há algumas normas que tratam do tema para ambientes de trabalho, tais como a Norma de Higiene Ocupacional NHO - 11 (Avaliação dos níveis de iluminamento em ambientes internos de trabalho); e a norma da Associação Brasileira de Normas Técnicas - ABNT NBR ISO/CIE 8995-1:2013 (Iluminação em ambientes de trabalho - Parte 1: Interior). A Norma Regulamentadora NR - 17 que trata de ergonomia (Escola Nacional da Inspeção do Trabalho, 2018) menciona a norma NHO - 11 como referência dos métodos recomendados para medições de níveis mínimos de iluminamento. Apesar das normas NHO - 11 e ISO/CIE 8995:2013 apresentarem similaridades em seus parâmetros de avaliação e medição da iluminação, optou-se nesse trabalho por adotar como referência principal esta última.

A norma ISO/CIE 8995:2013, além de recomendar a observância de aspectos como ofuscamento e uniformidade, recomenda para as áreas de trabalho do tipo ambientes de estudo a iluminância mínima de 500 lux com percentual de 10\% de tolerância (Associação Brasileira de Normas Técnicas, 2013). A iluminância é dita como o fluxo luminoso que é projetado numa unidade de área numa superfície. A unidade de medida da iluminância é o lux (Lx), que é a densidade do fluxo luminoso, ou seja, a quantidade de luz sobre uma determinada área (Niskier \& Macintyre, 2013). Um aparelho de iluminação, uma luminária, ou uma lâmpada emite lúmens. O Método dos Lúmens é o método de cálculo do sistema de iluminação artificial mais utilizado, devido principalmente à sua facilidade de utilização (Cuttle, 2010). 


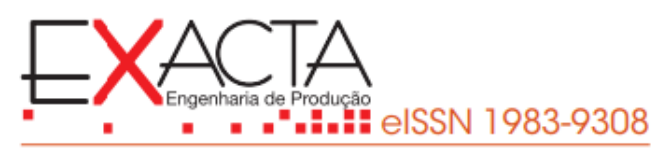

Para cada tipo de ambiente existe uma quantidade específica de lux, sendo medido com aparelhos, como o luxímetro que é instalado na altura do local onde é realizado o trabalho. O item 5 da norma ISO/CIE 8995:2013, trata dos requisitos para o planejamento da iluminação, apontando para ambientes de estudo, especificamente bibliotecas, que a iluminância mantida deverá ser igual a 500 lux.

Conforme ABNT NBR ISO/CIE 8995-1, o plano de trabalho é a área parcial em um local de trabalho no qual a tarefa visual está localizada e é realizada (Associação Brasileira de Normas Técnicas, 2013). O campo de trabalho em ambientes escolares pode ser, por exemplo, a área das mesas, carteiras, pranchetas, bancadas, dentre outros, visto que são as áreas utilizadas pelas pessoas para realizarem as suas atividades na maior parte do tempo.

Durante as avaliações deve ser considerada a luz do ambiente, seja ela natural, artificial ou ambas. São incontáveis as vantagens que a boa utilização da iluminação natural pode oferecer, tanto às atividades desenvolvidas no ambiente construído, quanto aos usuários nele inseridos. Estudos certificam que o ser humano e seu relógio biológico são favoráveis aos estímulos naturais que recebem principalmente da luz do dia em seus ambientes de trabalho, proporcionando uma sensação de bem-estar e em diversos benefícios para a saúde envolvendo aspectos fisiológicos, psicológicos e socioeconômicos (Nazzal, 2005). Apesar dessas inúmeras vantagens da luz natural, nem sempre é possível utilizar-se apenas dela, principalmente no desenvolvimento das atividades no período noturno, quando é necessária a luz artificial.

A iluminação artifícial é obtida, tendo como fonte as luminárias, cujos principais tipos são: incandescentes comuns, halógenas dicróicas, incandescentes halógenas, fluorescentes tubulares, fluorescentes compactas, lâmpadas à vapor de mercúrio, lâmpadas à vapor metálico e LEDs (Nazzal, 2005).

Diante disso, percebe-se a importância da adequação dos ambientes escolares quanto à iluminação de forma que atenda critérios técnicos de conforto e a legislação vigente sobre o tema.

\section{Metodologia}

A pesquisa foi realizada tendo como objeto de estudo as salas de um dos prédios padronizados para aulas de graduação de uma Instituição de Ensino Superior - IES pública localizada na cidade de Mossoró, a 280 km da capital do estado do Rio Grande do Norte. A Figura 1 representa a posição do prédio analisado e das respectivas salas de aula em relação ao norte. 
das carteiras escolares. Os pontos denominados B, C e D distanciaram-se paralelamente dos pontos $\mathrm{E}, \mathrm{F}$ e $\mathrm{G}$ em 5,00 m. A distância entre os pontos centrais $\mathrm{C}$ e $\mathrm{F}$ e os pontos paralelos a eles era de 2,40 $\mathrm{m}$. Os pontos próximos às paredes distaram $0,60 \mathrm{~m}$ delas. Os pontos $\mathrm{B}$ e $\mathrm{E}$ foram sempre próximos à parede das janelas, os pontos $\mathrm{D}$ e $\mathrm{G}$ sempre juntos à parede oposta $\mathrm{e}$ os pontos A, C e F, localizados no centro da sala, conforme a Figura 2.

Figura 2: Disposições dos pontos escolhidos para análise e distribuição das luminárias nas salas de aula

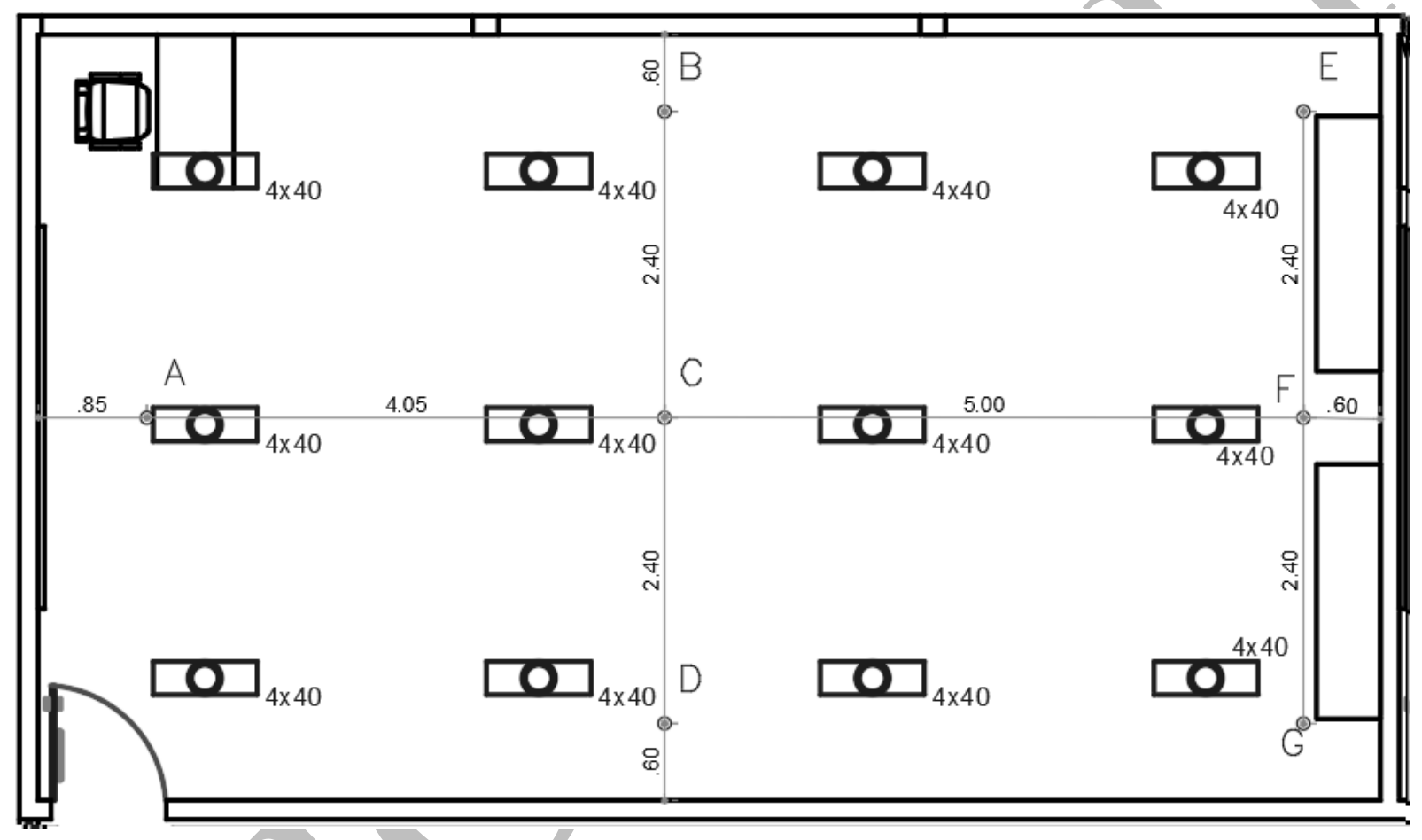

Fonte: Planta baixa cedida pelo setor responsável da IES e adaptada pelos autores, 2019.

As medições de iluminância foram realizadas nos meses de dezembro de 2019 e janeiro de 2020 e em dias de pleno sol por volta das 9:30 nos períodos matutinos, por volta das 15:30 nos períodos vespertinos e por volta das 18:00 nos períodos noturnos; na ausência de usuários para evitar interferência nos resultados.

Para a análise e comparação dos dados utilizou-se a metodologia indicada na norma ABNT NBR ISO/CIE 8995-1, registrando-se os dados nas planilhas de coleta e tratando-os com auxílio de planilhas eletrônicas. Utilizou-se como parâmetro o valor de 500 lux que consta no quadro do item 5 denominado "Requisitos para o planejamento da iluminação", da Norma ABNT NBR ISO/CIE 8995-1 (Associação Brasileira de Normas Técnicas, 2013), para ambientes de salas de aulas noturnas, classes e educação de adultos. Tais valores são indicados para projeto, entretanto, como não se teve acesso ao projeto de iluminação do 
recebe influência de sombreamento dos prédios circunvizinhos, ao contrário das demais salas do mesmo lado do prédio. Vale salientar que as salas 5 e 6 não apresentavam nenhuma luminária sem funcionamento, todavia as salas 9 e 10 apresentavam 1 luminária sem funcionamento, porém distantes do ponto A (Figura 3).

Figura 3: Iluminância nos pontos A, B, C, D, E, F e G das salas de aula analisadas

A

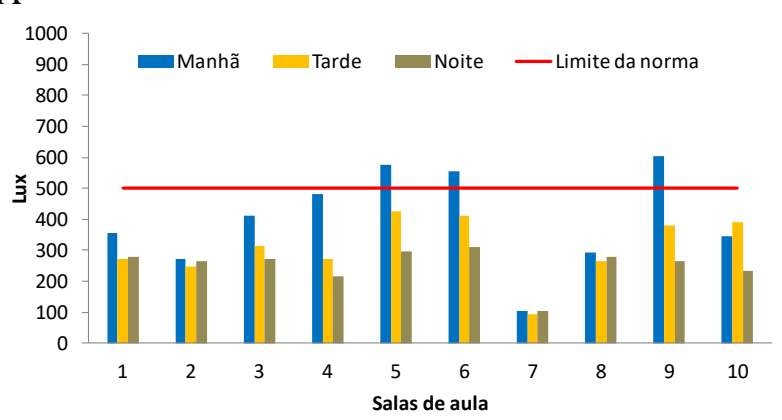

C

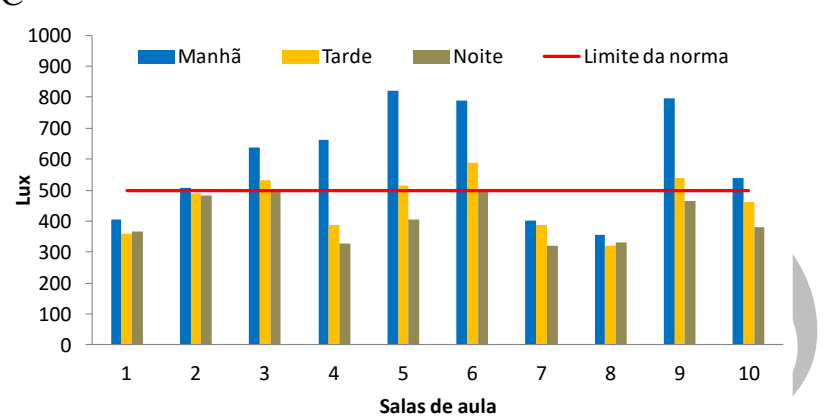

$\mathrm{E}$

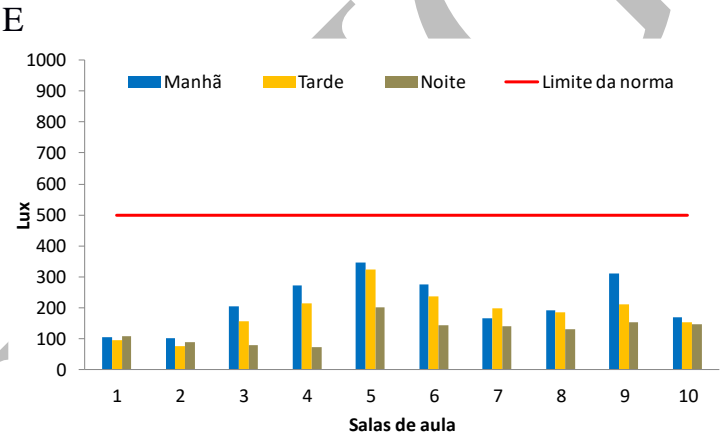

B

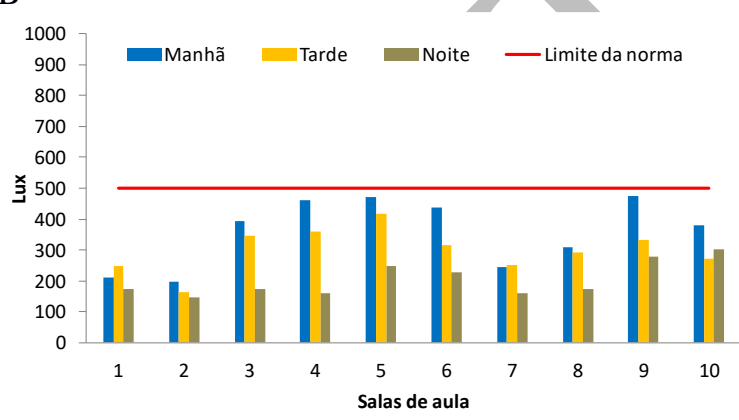

D

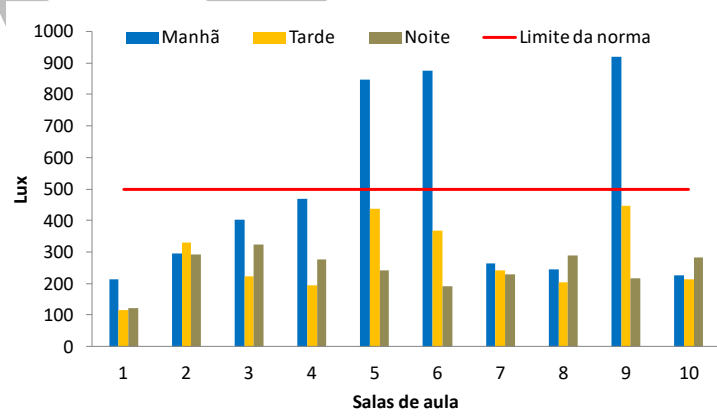

$\mathrm{F}$

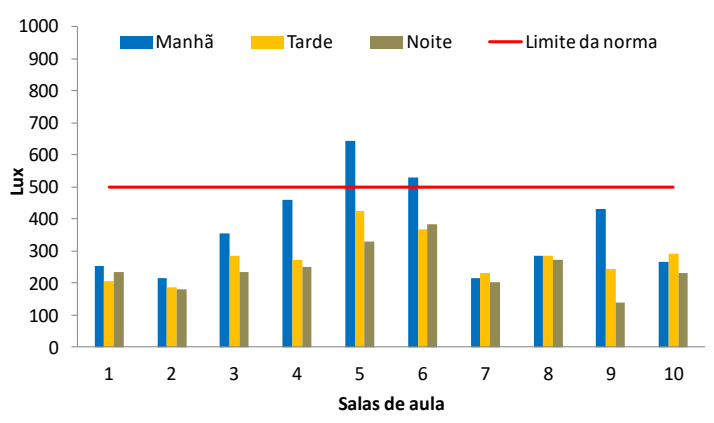


G

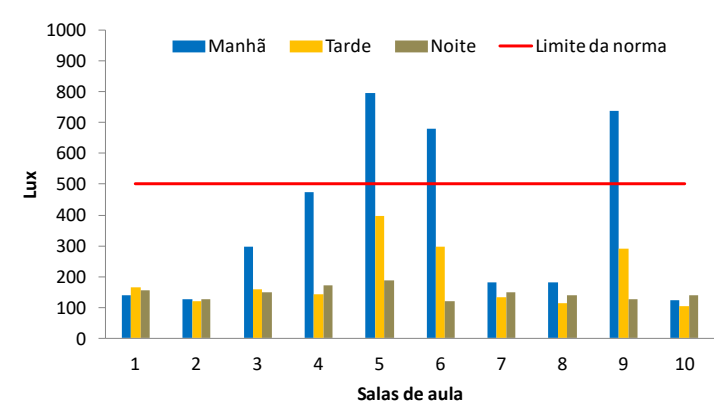

Fonte: Autoria própria, 2020.

No ponto B nenhum valor registrado atingiu o mínimo da norma nos turnos e salas analisadas. Porém, os valores mais próximos do mínimo foram os valores encontrados nas salas 3, 4, 5, 6 e 9, no turno da manhã, sendo estas as salas localizadas no lado leste do prédio.

O ponto médio das salas denominado $\mathrm{C}$ é o que apresenta maiores valores de iluminância em todas as salas e turnos, com exceção das salas 5, 6 e 9 no turno da manhã que obtiveram maiores valores no ponto D. Essas salas apresentam suas janelas voltadas para o lado leste sem influência de sombreamento dos prédios circunvizinhos nem da vegetação. No turno da manhã apenas as salas 1,7 e 8 no ponto $C$ não apresentaram valores que atendessem o limite mínimo estabelecido na norma. Já no turno da tarde apenas as salas 3, 5, 6 e 9 atenderam tal limite mínimo. No turno da noite, nenhum ponto com exceção do ponto C, nas salas 3 e 6 atendeu ao requisito da norma, além disso todas as luminárias dessas duas salas ( 3 e 6 ) estavam funcionando.

No ponto D apenas as salas 5, 6 e 9 apresentaram valores acima do nível mínimo da norma no turno da manhã. Esses valores foram os maiores encontrados dentre todos os obtidos nas medições desse estudo, podendo ser explicado pela proximidade desse ponto em relação às portas das salas, bem como a maior incidência da luz natural nessas salas que estão do lado leste do prédio. Além disso, a vegetação ao lado das janelas das salas 5, 6 e 9 é mais rala permitindo maior entrada de luz.

Os pontos Ge E podem ser influenciados pelo sombreamento de 2 condicionadores de ar tipo split fixados nas paredes de fundo de todas as salas, bem como pelo sombreamento das marquises do prédio. Embora o ponto E esteja mais próximo à parede com janela, não foram registrados valores de iluminância que atendessem o limite mínimo indicado na norma em nenhuma das salas e turnos analisados.

As salas 5, 6 e 9 apresentaram valores no ponto $\mathrm{G}$ acima do valor mínimo recomendado em norma no turno da manhã. As demais salas e turnos apresentaram valores abaixo do mínimo estabelecido. Nas salas 1, 2, 7, 8 e 10 verificou-se os menores valores no ponto $\mathrm{G}$ podendo ser 
explicado pelo fato de estarem localizadas do lado oeste do prédio, estando tais pontos sujeitos a influência externa do sombreamento dos prédios circunvizinhos e internamente pelos condicionadores de ar.

No ponto $\mathrm{F}$ apenas as salas 5 e 6 no turno matutino atenderam o requisito da norma, sendo na sala 5 onde se encontrou o maior valor de iluminância no turno da manhã. Pode-se justificar que além dessas salas estarem no lado leste do prédio a vegetação junto à sala 5 é mais rala, permitindo maior incidência da luz natural. As demais salas do mesmo lado do prédio (salas 3, 4 e 9) atingiram valores próximos ao mínimo da norma no turno da manhã.

\subsection{Análise da iluminância por salas}

Nas salas 1, 7 e 8 nenhum dos pontos nos três turnos apresentou valores de iluminância que atendessem o mínimo estabelecido na norma, estando essas salas no lado oeste do prédio e apresentando as maiores quantidades de luminárias sem funcionamento: três luminárias nas salas 1 e 7, e duas na sala 8 . Os maiores valores encontrados nessas salas foram no ponto $\mathrm{C}$, respectivamente, 354 lux na sala 1, 401 lux na sala 7 e 405 lux na sala 8 . Os menores valores nessas mesmas salas foram observados no turno da tarde, a saber: 93 lux na sala 1, no ponto E; 92 lux na sala 7, no ponto A; e 113 lux na sala 8, no ponto $\mathrm{G}$.

Nas salas 2, 4 e 10, apenas o ponto C, no turno da manhã, apresentou valores que atingiram o mínimo estabelecido em norma, sendo eles: 508 lux, 661 lux e 540 lux. As salas 2 e 10 estão no lado oeste do prédio enquanto a sala 4 está do lado leste. Na parte externa da sala 4 observou-se a vegetação na altura das janelas, podendo influenciar na passagem de luz natural. Entretanto, as salas 2 e 4 não apresentam nenhuma luminária sem funcionamento. A sala 10 apresenta apenas uma luminária sem funcionamento, mas esta encontra-se distante do ponto C, sendo mais próxima do ponto E. Conforme apresentado na Figura 4. 
Figura 4: Iluminância nas salas por ponto de medição

\section{Sala 1}

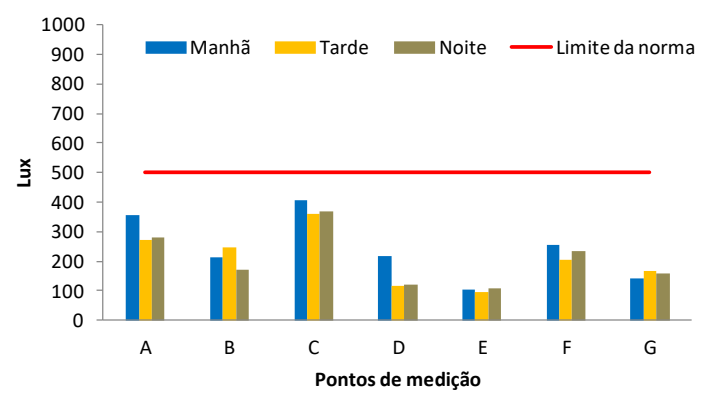

\section{Sala 3}

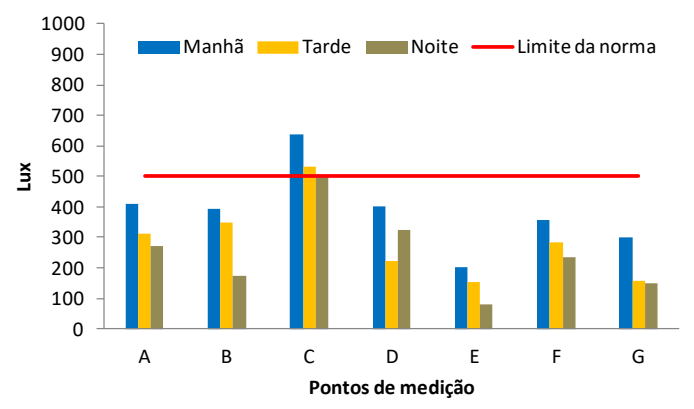

\section{Sala 5}

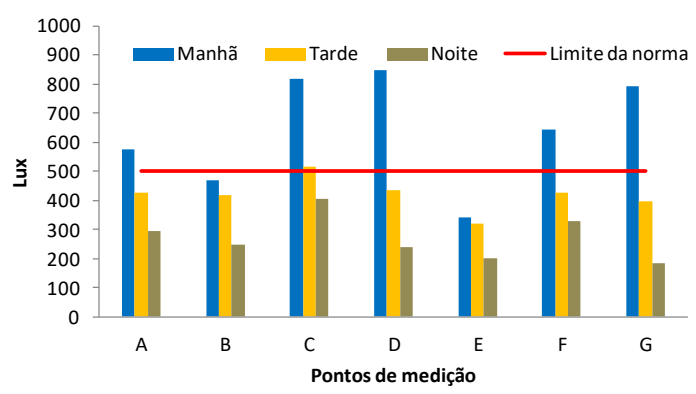

\section{Sala 7}

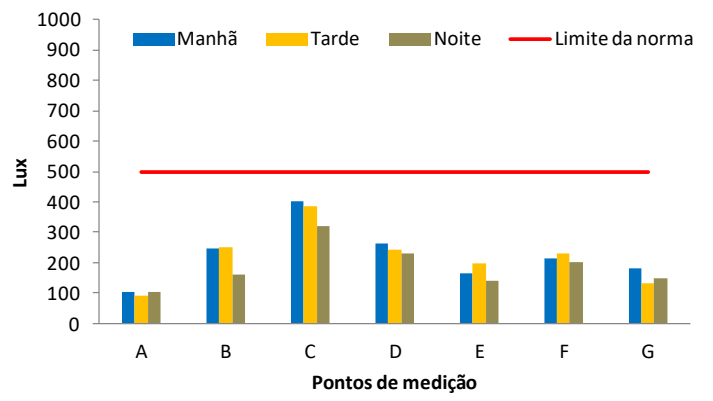

Sala 2

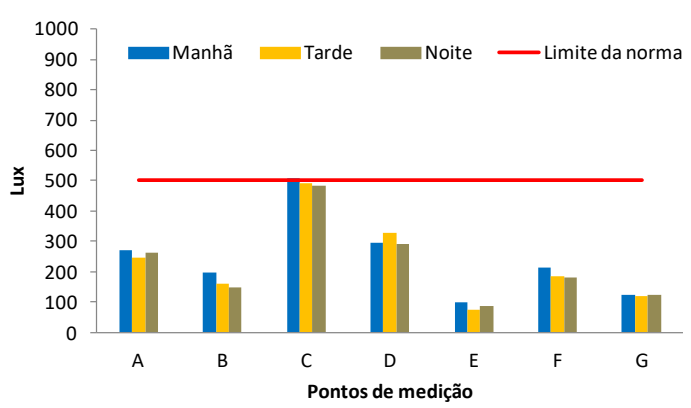

Sala 4

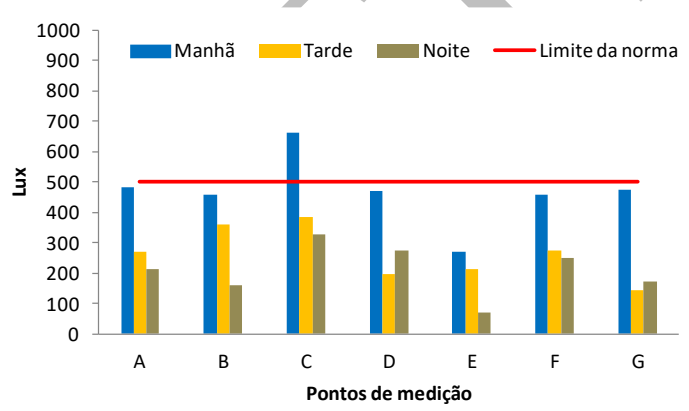

Sala 6

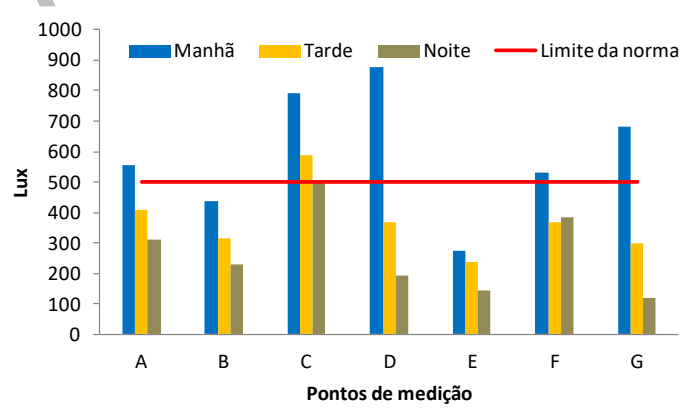

Sala 8

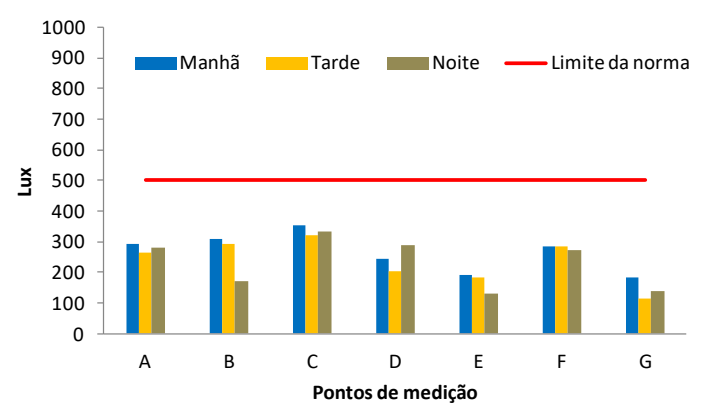


Sala 9

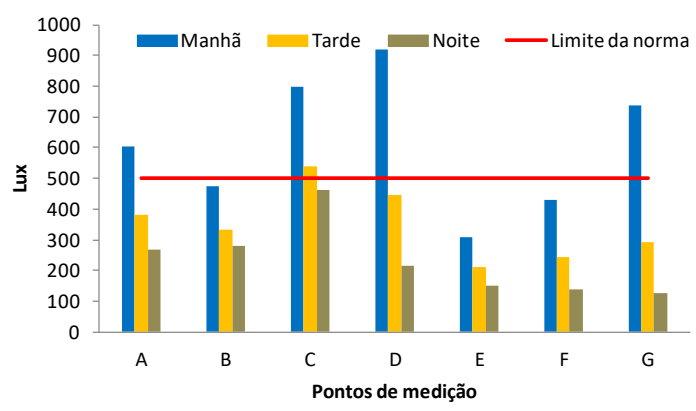

Sala 10

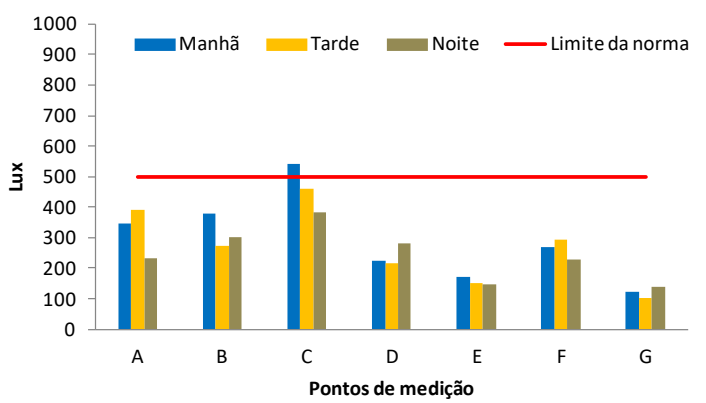

Fonte: Autoria própria, 2020.

$\mathrm{Na}$ sala 3, apenas o ponto $\mathrm{C}$ apresentou valores que atendem a norma nos três turnos avaliados sendo os valores 638 lux, 532 lux e 501 lux, respectivamente nos turnos da manhã, tarde e noite. Já as medições nos demais pontos ficaram abaixo dos limites estabelecidos, sendo o ponto E o mais crítico.

Na sala 9, no turno da manhã, os valores medidos nos pontos A, C, D e G atenderam o mínimo estabelecido na norma, sendo respectivamente: 602 lux, 798 lux, 920 lux e 738 lux. No turno da tarde apenas no ponto $\mathrm{C}$ verificou-se um valor de $539 \mathrm{lux}$, atendendo assim a norma.

Assim como a sala 9, as salas 5 e 6 estão no lado leste do prédio apresentando a maior quantidade de pontos com valores que atendem aos requisitos normativos. Dos sete pontos avaliados, cinco deles apresentaram valores dentro dos critérios da norma no turno da manhã, sendo estes os pontos: A, C, D, F e G. Os pontos B e E não atingiram os valores da norma, o que pode ser uma influência do sombreamento da marquise desta parte do prédio no horário de medição desse turno, estando os pontos próximos às janelas. Já no turno da tarde apenas o ponto $\mathrm{C}$ dessas salas apresentou valores que atingiram o mínimo da norma, sendo respectivamente 516 lux e 587 lux. No turno da noite apenas o ponto C da sala 6 atingiu o valor mínimo com 502 lux medidos.

\subsection{Análise da iluminância por turno}

O turno da manhã foi o que apresentou a maior quantidade de pontos de medição com valores que atendem o mínimo de iluminância estabelecido por norma, totalizando 18 dos 70 pontos de medição. Já o turno da tarde apresentou valores que atenderam a norma em 4 pontos sendo todos eles no ponto C. No turno da noite foi identificado a maior quantidade de pontos que não atingiu o mínimo estabelecido na norma e apenas 2 pontos cumpriu tal critério, sendo 
esses dois valores identificados também no ponto C. O Quadro 1 apresenta os valores medidos em lux, no turno da manhã, nos pontos avaliados nas 10 salas.

Quadro 1: Valores de iluminância (em lux) medidos nas 10 salas nos 7 pontos no período matutino

\begin{tabular}{|c|c|c|c|c|c|c|c|}
\hline Salas & Ponto A & Ponto B & Ponto C & Ponto D & Ponto E & Ponto F & Ponto G \\
\hline 1 & 356 & 212 & 405 & 215 & 104 & 255 & 140 \\
\hline 2 & 270 & 197 & 508 & 295 & 100 & 215 & 125 \\
\hline 3 & 410 & 394 & 638 & 403 & 203 & 355 & 298 \\
\hline 4 & 483 & 460 & 661 & 470 & 272 & 458 & 475 \\
\hline 5 & 576 & 472 & 820 & 847 & 344 & 644 & 795 \\
\hline 6 & 556 & 436 & 790 & 876 & 274 & 530 & 680 \\
\hline 7 & 102 & 246 & 401 & 264 & 165 & 216 & 182 \\
\hline 8 & 294 & 309 & 354 & 244 & 190 & 284 & 182 \\
\hline 9 & 602 & 473 & 798 & 920 & 310 & 430 & 738 \\
\hline 10 & 346 & 380 & 540 & 225 & 170 & 267 & 123 \\
\hline
\end{tabular}

Fonte: Autoria própria, 2020.

No turno da manhã o ponto que se destacou com maior quantidade de valores acima do mínimo estabelecido em norma foi o ponto $\mathrm{C}$ e as salas 5 e 6 . As salas 1,7 e 8 ; bem como os pontos B e E não apresentaram valores que atendessem ơ estabelecido em norma. Esse resultado pode ser justificado pelo fato das salas 5 e 6 estarem do lado leste e todas as luminárias funcionando. Por outro lado, as salas 1, 7 e 8 estão localizadas no lado oeste e apresentam o maior número de luminárias sem funcionamento.

No turno da tarde apenas o ponto $\mathrm{C}$ das salas 3, 5, 6 e 9 apresentou valores que atenderam a norma. Isso pode ser justificado porque o ponto $\mathrm{C}$ está no ponto médio das salas podendo receber influência da iluminação das outras luminárias. Além disso, todas as luminárias das salas 3, 5 e 6 estavam funcionando e na sala 9 somente uma delas não funcionava, porém, localizada mais distante do ponto C. O Quadro 2 apresenta os valores medidos em lux, no turno da tarde, nos pontos avaliados nas 10 salas. 
Quadro 2: Valores de iluminância (em lux) medidos nas 10 salas nos 7 pontos no período vespertino

\begin{tabular}{|c|c|c|c|c|c|c|c|}
\hline Salas & Ponto A & Ponto B & Ponto C & Ponto D & Ponto E & Ponto F & Ponto G \\
\hline 1 & 270 & 248 & 359 & 116 & 93 & 206 & 165 \\
\hline 2 & 246 & 162 & 491 & 330 & 76 & 186 & 121 \\
\hline 3 & 312 & 347 & 532 & 224 & 155 & 284 & 159 \\
\hline 4 & 271 & 360 & 386 & 196 & 212 & 273 & 144 \\
\hline 5 & 426 & 417 & 516 & 436 & 322 & 426 & 397 \\
\hline 6 & 410 & 316 & 587 & 368 & 237 & 369 & 298 \\
\hline 7 & 92 & 250 & 387 & 241 & 198 & 232 & 134 \\
\hline 8 & 264 & 292 & 319 & 204 & 184 & 286 & 113 \\
\hline 9 & 380 & 331 & 539 & 446 & 210 & 245 & 291 \\
\hline 10 & 391 & 273 & 461 & 214 & 151 & 293 & 103 \\
\hline
\end{tabular}

Fonte: Autoria própria, 2020.

O período noturno foi o que apresentou o menor número de pontos que atenderam o valor mínimo estabelecido na norma, sendo eles o ponto $C$ nas salas 3 e 6 . Nessas salas não se identificou nenhuma luminária sem funcionamento. Embora não tenha atingido o valor mínimo requisitado na norma, o ponto $\mathrm{C}$ nas demais salas apresentou os maiores valores em relação aos demais pontos avaliados. Possivelmente, por esse ponto estar no ponto médio das salas recebe influência de iluminação circunvizinha das demais luminárias. No Quadro 3 constam os valores medidos em lux, no turno da noite, nos pontos avaliados nas 10 salas.

Quadro 3:Valores de iluminância (em lux) medidos nas 10 salas nos 7 pontos no período noturno

\begin{tabular}{|c|c|c|c|c|c|c|c|}
\hline Salas & Ponto A & Ponto B & Ponto C & Ponto D & Ponto E & Ponto F & Ponto G \\
\hline 1 & 280 & 172 & 368 & 122 & 108 & 235 & 157 \\
\hline 2 & 264 & 147 & 482 & 291 & 89 & 182 & 125 \\
\hline 3 & 273 & 175 & 501 & 324 & 79 & 236 & 150 \\
\hline 4 & 215 & 160 & 327 & 276 & 71 & 249 & 172 \\
\hline 5 & 297 & 248 & 405 & 241 & 202 & 330 & 187 \\
\hline 6 & 311 & 229 & 502 & 192 & 142 & 384 & 120 \\
\hline 7 & 102 & 160 & 320 & 230 & 140 & 203 & 150 \\
\hline 8 & 280 & 172 & 332 & 288 & 130 & 274 & 140 \\
\hline 9 & 266 & 279 & 464 & 216 & 152 & 140 & 128 \\
\hline 10 & 232 & 302 & 382 & 282 & 147 & 230 & 140 \\
\hline
\end{tabular}

Fonte: Autoria própria, 2020.

Portanto, dos sete pontos avaliados, o ponto $\mathrm{C}$ se destacou dos demais. Já com relação às salas de aulas, as de número 5 e 6 apresentaram melhores valores de iluminância, seguidas da de 


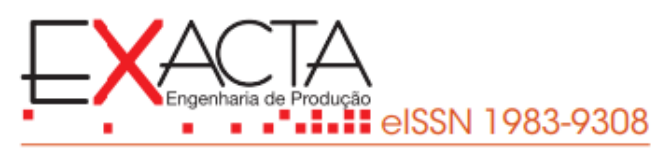

número 9. Em relação aos turnos, no período matutino obteve-se os maiores valores de iluminância, atendendo ao mínimo estabelecido na norma.

\subsection{Análise da uniformidade}

Os resultados referentes à uniformidade das salas de aula variaram nos três turnos analisados. O maior valor identificado foi na sala 5 no turno da tarde $(U=76 \%)$; e o menor valor na sala 3 no turno da noite $(\mathrm{U}=33 \%)$. Os valores da uniformidade nas dez salas nos três turnos estão apresentados no Quadro 4.

Quadro 4: Valores da uniformidade por sala e por turno

\begin{tabular}{|c|c|c|c|}
\hline \multirow{2}{*}{ Salas } & \multicolumn{3}{|c|}{ Turno } \\
\cline { 2 - 4 } & Manhã & Tarde & Noite \\
\hline 1 & $43,15 \%$ & $44,68 \%$ & $52,43 \%$ \\
\hline 2 & $40,94 \%$ & $33,00 \%$ & $39,43 \%$ \\
\hline 3 & $52,61 \%$ & $53,90 \%$ & $31,82 \%$ \\
\hline 4 & $58,07 \%$ & $54,72 \%$ & $33,81 \%$ \\
\hline 5 & $53,53 \%$ & $76,67 \%$ & $68,53 \%$ \\
\hline 6 & $46,31 \%$ & $64,18 \%$ & $44,68 \%$ \\
\hline 7 & $45,30 \%$ & $41,98 \%$ & $54,71 \%$ \\
\hline 8 & $68,61 \%$ & $47,59 \%$ & $56,31 \%$ \\
\hline 9 & $50,81 \%$ & $60,20 \%$ & $54,47 \%$ \\
\hline 10 & $41,98 \%$ & $38,23 \%$ & $57,14 \%$ \\
\hline Máximo & $68,61 \%$ & $76,67 \%$ & $68,53 \%$ \\
\hline Mínimo & $40,94 \%$ & $33,00 \%$ & $31,82 \%$ \\
\hline Amplitude & $27,67 \%$ & $43,66 \%$ & $36,72 \%$ \\
\hline
\end{tabular}

Fonte: Autoria própria, 2020.

Os valores de uniformidade identificados nas salas indicam que a iluminação natural influencia negativamente nos resultados. Nota-se que as salas que recebem maior incidência de luminosidade natural no turno da manhã (salas 3, 4, 5, 6, e 9) apresentaram uniformidade menor em relação ao turno da tarde. Já nas salas que recebem maior incidência de luminosidade natural no turno da tarde (salas $1,2,7,8$ e 10) foi onde se obtive melhor uniformidade no turno da manhã (salas 2 e 8) ou no turno da noite (salas 1, 7 e 10).

Em relação aos turnos, pela manhã ocorreu a menor amplitude de iluminância $(27,67 \%)$, seguido dos turnos da noite $(36,72 \%)$ e da tarde $(43,66 \%)$, respectivamente. No turno da manhã o máximo valor de iluminância ocorreu na sala $8(U=68,61 \%)$ e o mínimo na sala 2 $(\mathrm{U}=40,94 \%)$, sendo estes os maiores valores dessas salas. No turno da tarde o menor valor 


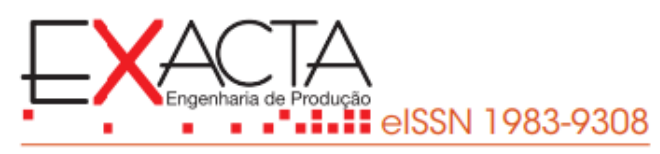

por sua direta relação com o desenvolvimento nos âmbitos humano, tecnológico, cultural, econômico, da cidadania, entre outros, que são inerentes à educação numa concepção de formação para a cidadania e para o trabalho.

\section{Conclusões}

Tendo em vista a relevância e abrangência do tema, a presente pesquisa alcançou os objetivos propostos ao apresentar uma análise dos níveis de iluminância de dez salas de um dos prédios padronizados para aulas de graduação de uma Instituição de Ensino Superior - IES pública localizada na cidade de Mossoró-RN. De forma geral, os resultados obtidos possibilitam concluir que os valores de iluminância média dessas salas de aulas estão abaixo do recomendado pela norma NBR ISO 8995-1 em 3 das 10 salas avaliadas, apresentando assim uma iluminação insuficiente para os fins a que as salas se destinam, podendo causar prejuízos à saúde dos seus usuários, mal-estar e diminuição nos níveis de aprendizagem dos alunos e desempenho de professores reduzindo assim o seu rendimento escolar. Nas demais salas, pelo menos em um dos turnos, algum ponto de medição apresentou valores médios que atendem às especificações da norma.

Em relação ao coeficiente de uniformidade, todas as salas exceto a sala 5 no turno vespertino apresenta valores abaixo do mínimo recomendado na norma NBR ISO/CIE 8995-1.

Vários fatores podem ter influenciado no nível de iluminação das salas de aula, como a presença de luminárias defeituosas, a execução parcial do projeto de iluminação, a não consideração durante a elaboração do projeto de iluminação de aspectos da arquitetura do prédio e do seu entorno, bem como a arborização e os recursos de diminuição de luminosidade natural com o uso de brises e películas.

Dessa forma, espera-se ter contribuído numa abordagem de ergonomia e segurança ocupacional com o conhecimento sobre iluminância em ambientes de estudo e sua influência na produtividade e conforto dos usuários desses ambientes.

$\mathrm{Na}$ execução da pesquisa algumas dificuldades foram encontradas, tais como o acesso ao projeto de iluminação do prédio objeto do estudo, pois os projetos são disponibilizados para o corpo técnico do setor de obras e manutenção e para se ter acesso são necessários procedimentos burocráticos. Outra dificuldade foi a realização das medições precisaram ser feitas em momentos em que as salas estivessem vazias, entretanto, os horários das 9:30 e 15:30 geralmente são horários de aula. Por isso as medições foram realizadas no final do 


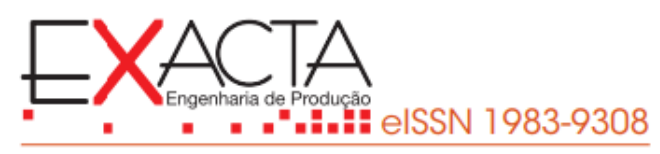

semestre letivo em dias próximos ao recesso de fim de ano, pois nesse período os professores realizaram menos atividades em sala de aula.

Como sugestões de trabalhos futuros podem ser realizadas pesquisas de conforto em ambientes de estudos, avaliação de ofuscamentos e reflexos em ambientes universitários, tais como salas de aula, bibliotecas, laboratórios de informática, laboratórios de desenho, entre outros; trabalhos sobre psicodinâmica das cores em ambientes de estudo; pesquisas sobre a eficiência energética considerando diferentes configurações do projeto de iluminação, de configurações de luminárias e conforto visual; trabalhos sobre a influência da uniformidade nesses ambientes; aplicação de questionários para identificação da percepção de conforto lumínico de usuários, dentre outros.

\section{Referências}

Associação Brasileira de Normas Técnicas. (2013). NBR ISO/CIE 8995-1 - Iluminação de ambientes de trabalho, Parte 1: Interior. 1-54.

Athanázio-Heliodoro, J. C., Zaruma, D. G., Pupo, C. H., \& Fenner, P. T. (2017). Análise de iluminância no ambiente de trabalho. Revista Ciência do Trabalho, 7(1), 109-120.

Bortolan, G. M. Z., Ferreira, M. G. G., \& Tezza, R. (2020). Elaboração de um instrumento de avaliação para medir desconforto visual subjetivo de funcionários de lojas de moda. Revista Design \& Tecnologia, 10(20), 22-33. https://doi.org/10.23972/det2020iss20pp22-3

Cuttle, C. (2010). Towards the third stage of the lighting profession. Lighting Research and Technology, 42(1), 73-93. https://doi.org/10.1177/1477153509104013

Dianat, I., Sedghi, A., Bagherzade, J., Jafarabadi, M. A., \& Stedmon, A. W. (2013). Objective and subjective assessments of lighting in a hospital setting: Implications for health, safety and performance. Ergonomics, 56(10), 1535-1545.

https://doi.org/10.1080/00140139.2013.820845

Escola Nacional da Inspeção do Trabalho - ENIT. Norma Regulamentadora NR - 17. (2018). Portaria MTb n. 3214, de 08 de junho de 1978 alterada pela Portaria MTb n. 876, de 24 de outubro de 2018.

Hsieh, M. C., Hong, L. Y., Wang, E. M. Y., Chao, W. C., Yang, C. C., \& Su, L. C. (2020). Effect of correlated colour temperature and illuminance levels on user's visual 
perception under LED lighting in Taiwan. Ergonomics, 63(2), 175-190.

https://doi.org/10.1080/00140139.2019.1699964

Hybiner, J. M. B. M. (2015). Análise da iluminação em salas de aulas de escolas da rede de ensino pública das superintendências regionais de ensino de juiz de fora, Ponte Nova e Ubá, $M G$. Universidade Federal de Viçosa.

Juslén, H. T., Wouters, M. C. H. M., \& Tenner, A. D. (2007). Lighting level and productivity: A field study in the electronics industry. Ergonomics, 50(4), 615-624. https://doi.org/10.1080/00140130601155001

Kowaltowski, D. K. (2011). Arquitetura escolar: o projeto do ambiente de ensino. Oficina de Textos.

Kroemer, K. H. E., \& Grandjean, E. (2005). Manual de ergonomia: adaptando o trabalho ao homem (5th ed.). Bookman.

Losekan, I., Franz, L. A. dos S., Pereira, A. S., \& Bolzan, L. M. (2021). Condicionantes ergonômicos na organização do trabalho docente: uma revisão sistemática da literatura. Exacta, 19(4). https://doi.org/https://doi.org/10.5585/exactaep.2021.18252

Magalhães, E. N., \& Vieira, E. M. (2017). Análise do conforto ambiental e ergonômico em uma instituição de ensino. Revista Sustinere, 5(2), 317-337.

https://doi.org/10.12957/sustinere.2017.30168

Mascarenhas, S. (2012). Metodologia Científica (1st ed.). Pearson Education do Brasil.

Mendes, L. H. D., \& Bergiante, N. C. R. (2018). Promoção da qualidade de vida no trabalho em bibliotecás universitárias através da aplicação da ergonomia. Brazilian Journal of Development, 4(6), 2774-2793.

Moraes, L. N., \& Claro, A. (2013). Estudo comparativo de sistemas de iluminação artificial considerando luz natural e consumo de energia. Ambiente Construído, 13(4), 59-74. https://doi.org/10.1590/s1678-86212013000400005

Nazzal, A. A. (2005). A new evaluation method for daylight discomfort glare. International Journal of Industrial Ergonomics, 35(4), 295-306. https://doi.org/10.1016/j.ergon.2004.08.010

Niskier, J., \& Macintyre, A. J. (2013). Instalações elétricas (6th ed.). LTC.

Robert, L. de F. O. de J., Pinto, J. M. B., Almeida, B. L. de, Tavares, J. F. C. M., \& Mendes, J. M. (2020). Análise do nível de iluminamento em um Instituto de Ensino Federal, em Belém-PA. Tecno-Lógica, 24(Especial), 324-333. https://doi.org/10.17058/tecnolog.v2i0.15756 


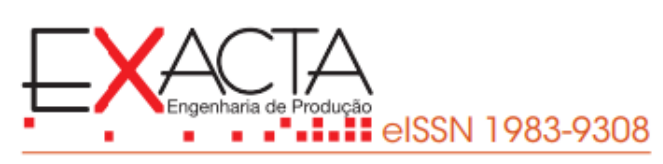

Rodrigues, A. M., Zeviani, C. H., Rebelato, M. G., \& Borges, L. (2015). Avaliação de desempenho ambiental industrial: elaboração de um referencial metodológico. Revista Produção Online, 15(1), 101. https://doi.org/10.14488/1676-1901.v15i1.1719 